\title{
Effect of Potential, Temperature, and Fluoride Ions on the Repassivation Kinetics of Titanium in Phosphate Buffered Saline Solution with the Photon Rupture Method
}

\author{
Masatoshi Sakairi, Hiroomi Miyata, Tatsuya Kikuchi, and Hideaki Takahashi \\ Division of Materials Science and Engineering, Graduate School of Engineering, Hokkaido University, \\ Kita-13, Nishi-8, Kita-ku, Sapporo, 060-8628, Japan \\ Correspondence should be addressed to Masatoshi Sakairi, msakairi@eng.hokudai.ac.jp
}

Received 15 February 2009; Revised 24 April 2009; Accepted 5 May 2009

Recommended by Margarita Martin

\begin{abstract}
The effect of the applied potentials, temperature, and $\mathrm{F}^{-}$ions on the localized repassivation kinetics of titanium was investigated by the photon rupture method, PRM, and electrochemical techniques in phosphate buffered saline solution. The log $I$ versus $\log t$ plots after laser beam irradiation showed a rapid increase, then a decrease with a slope of about -1.5 , which is steeper than that expected from high field oxide film formation theory, suggesting that the repassivation of titanium is a combination of electrochemical and chemical reactions. The repassivation current increases with increases in the applied potential and addition of $\mathrm{F}^{-}$ions, while solution temperature does not influence the repassivation kinetics. The effect of $\mathrm{F}^{-}$ions on the repassivation kinetics can be explained by localized $\mathrm{pH}$ changes caused by very rapid dissolution of titanium when titanium was exposed to PBS solution.
\end{abstract}

Copyright ( $) 2009$ Masatoshi Sakairi et al. This is an open access article distributed under the Creative Commons Attribution License, which permits unrestricted use, distribution, and reproduction in any medium, provided the original work is properly cited.

\section{Introduction}

Air formed oxide films or native oxide films on titanium and its alloys play a very important role in biocompatibility and corrosion resistance, however, the oxide films may be removed or destroyed mechanically or chemically during service. This oxide film breakdown may be a cause of further, continuous dissolution of the underlying metals, and as metals are dissolved in vitro, the increase in metal ion concentration may induce cell death near the dissolving metals. Therefore, many papers have investigated corrosion of metals, mainly titanium alloys and stainless steels both in vitro and in vivo [1-10]. Karthega et al. [6] reported on the electrochemical behavior of $\beta$-titanium alloys in Hank's solutions. Cheng et al. [7] studied crevice corrosion resistance of NiTi in Hanks' solutions. Reclaru and Meyer [11] reported corrosion in the presence of a titanium implants and dental alloys. Khan et al. [12] reported corrosion and wear of titanium alloys in biological environments. Suba et al. [13] examined the morphological changes in vitro and in vivo of the $\mathrm{Ti} / \mathrm{TiO}_{2}$ layer and the surface changes induced by mechanical scratching of samples. Handzlik and Fitzner [14] reported electronic properties of anodic oxide films formed on titanium in phosphate buffered saline solution and artificial saliva.

When titanium and its alloys are used in dental applications, the oxide films on them are removed by brushing and when in contact with foods, and then usually repassivate. Understanding the repassivation kinetics is very important for understanding corrosion and protection of metals, both in dental and other applications. Therefore, there are many papers related to repassivation behavior using mechanical oxide film stripping techniques [15-18]. Burstein and liu $[15,16]$ used a guillotine electrode technique to investigate repassivation kinetics. Tsuru and Sakairi [18] have reported breakdown and repassivation of passive oxide film of iron whiskers by a mechanical deformation method. Conventional mechanical oxide film stripping techniques, however, suffer from disadvantages, such as slow rates of stripping, contamination of exposed surfaces from the 
TABLE 1: Chemical composition of titanium (mass\%).

\begin{tabular}{lccccr}
\hline Fe & $\mathrm{O}$ & $\mathrm{N}$ & $\mathrm{C}$ & $\mathrm{H}$ & $\mathrm{Ti}$ \\
\hline 0.02 & 0.05 & 0.01 & 0.01 & 0.003 & bal. \\
\hline
\end{tabular}

stripping tools, and stresses and strains on the substrate during film stripping. In the last 15 years, there are reports of film stripping by focused pulsed Nd-YAG-laser beam irradiation (Photon Rupture Method, PRM, or laser impact), which solves many of the problems caused by mechanical oxide film stripping [19-25]. The irradiation with a pulsed laser beam is able to strip oxide film at extremely high rates without contamination from the film removing tools [19]. Itagaki et al. [20] reported the amount of dissolution of iron during repassivation from a freshly generated surface by using pulsed laser beam irradiation and a channel flow double electrode. Some of the authors here [21-25] have reported on the repassivation kinetics and the initial stage of localized corrosion behavior of coated steels by PRM combined with electrochemical techniques.

From a practical point of view, titanium alloys are usually used as a biomaterial, so, it is important to examine the repassivation behavior of titanium alloys both in vivo and in vitro. However, alloying elements and in vivo experiments sometimes make it difficult to understand the repassivation kinetics, therefore, commercially available pure titanium was used as specimens and in vitro experimental conditions were investigated in the present study. There are many kinds of artificial body fluids, and the phosphate buffered saline solution in this study was selected as an artificial body fluid, because of its buffer reaction, $\mathrm{pH}$, and stability.

The purpose of this study is to apply the PRM to investigate the effects of the applied potentials and temperature on the repassivation kinetics of titanium in phosphate buffered saline solutions. Some commercially available tooth pastes contain $\mathrm{NaF}$ or other $\mathrm{F}$ containing compounds, meaning that $\mathrm{F}^{-}$ion and/or HF may be formed during brushing. If titanium containing dental implants are used, and bare metal surfaces are exposed to $\mathrm{F}^{-}$or HF containing solutions, it is well known that titanium easily dissolves in the presence of $\mathrm{F}^{-}$ions especially at low $\mathrm{pH}$ [26]. To investigate only the effect of $\mathrm{F}^{-}$ions on repassivation kinetics of titanium, phosphate buffered saline solution with dissolved $\mathrm{NaF}$ was used in the present study. To examine the effect of $\mathrm{F}^{-}$ions on the repassivation kinetics of commercial pure titanium by PRM and to elucidate the role of $\mathrm{F}^{-}$ions on the repassivaion kinetics is also a purpose of this study.

\section{Experimental}

Specimens. Titanium sheet (thickness $0.3 \mathrm{~mm}$, Niraco Co.) of 99.9 mass $\%$ Ti was cut into $10 \times 20 \mathrm{~mm}^{2}$ coupons, and the chemical composition of the sheet is as shown in Table 1 . The specimens were cleaned for 300 second in ethanol and in doubly distilled water, ultrasonically; then electropolished at a constant cell voltage of $10 \mathrm{~V}$ in $3 \mathrm{kmol} \mathrm{m}^{-3} \mathrm{H}_{2} \mathrm{SO}_{4}$ ethanol solution at $253 \mathrm{~K}$ for 60 second.

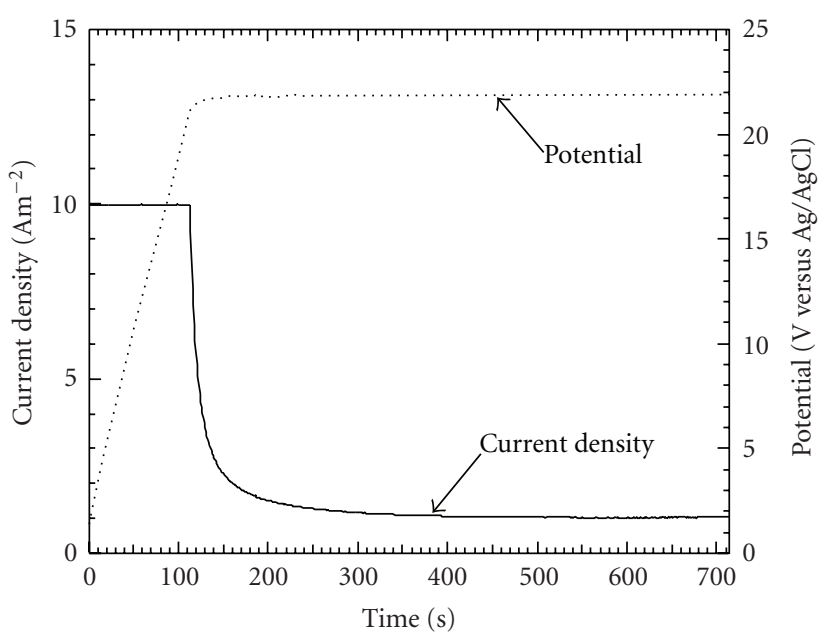

FIGURE 1: Changes in current and potential during anodizing in $0.5 \mathrm{kmol} \mathrm{m}^{-3} \mathrm{H}_{3} \mathrm{BO}_{4} / 0.05 \mathrm{kmol} \mathrm{m}^{-3} \mathrm{Na}_{2} \mathrm{~B}_{4} \mathrm{O}_{7}$ solution.

Counter and reference electrodes. Pt plate was used as the counter electrode and an $\mathrm{Ag} / \mathrm{AgCl}(\mathrm{KCl}$ sat.) electrode was used as the reference electrode in the anodizing and electrochemical measurements.

Protective film formation. In this study, barrier type anodic oxide films were used as the protective film to avoid electrochemical reactions at areas that were not laser beam irradiated. The anodizing was carried out in $0.5 \mathrm{kmol}$ $\mathrm{m}^{-3} \mathrm{H}_{3} \mathrm{BO}_{4} / 0.05 \mathrm{kmol} \mathrm{m}^{-3} \mathrm{Na}_{2} \mathrm{~B}_{4} \mathrm{O}_{7}$ solution at $293 \mathrm{~K}$ at a constant anodic current density of $10 \mathrm{~A} \mathrm{~m}^{-2}$ up to a potential of $22 \mathrm{~V}$, then kept at this anodic potential for 600 second. Figure 1 shows the changes in current and potential during the barrier type oxide film formation. From the final anodizing potential, the color of the specimens, and a previous report [27], the formed anodic oxide film thickness was estimated to be about $70 \mathrm{~nm}$.

Solution. A Phosphate Buffered Saline solution, PBS, $8.1 \mathrm{~mol} \mathrm{~m}^{-3} \mathrm{Na}_{2} \mathrm{HPO}_{4}+1.5 \mathrm{~mol} \mathrm{~m}{ }^{-3} \mathrm{KH}_{2} \mathrm{PO}_{4}+137 \mathrm{~mol}$ $\mathrm{m}^{-3} \mathrm{NaCl}+2.7 \mathrm{~mol} \mathrm{~m}^{-3} \mathrm{KCl}$, was used as the electrolyte. To investigate the influence of $\mathrm{F}^{-}$ions, $24 \mathrm{~mol} \mathrm{~m}^{-3} \mathrm{NaF}$ was added to the PBS.

Polarization behavior. To determine the applied potential for measuring the repassivation kinetics, the polarization behavior of electropolished specimens were measured by the linear potential sweep method in PBS and PBS with NaF at $296 \mathrm{~K}$, with a sweep rate $=0.33 \mathrm{mV} / \mathrm{s}$.

Repassivation kinetics. The anodized specimens were immersed in the solutions, and a potential $(-0.2 \mathrm{~V}$ to $1.5 \mathrm{~V})$ was applied while controlling the temperature, thereafter the specimens were irradiated by one focused pulse of the pulsed laser beam. Figure 2 shows a schematic outline of the PRM test equipment. The current transient after the irradiation was measured by a digital oscilloscope (Yokogawa co., DL708E) connected to a personal computer. The NdYAG laser (Sepctra Physics GCR-130) apparatus used in this study was at a wavelength of $532 \mathrm{~nm}$, wave duration 8 nanosecond, frequency $10 \mathrm{~s}^{-1}$, and beam power $30 \mathrm{~mW}$. 


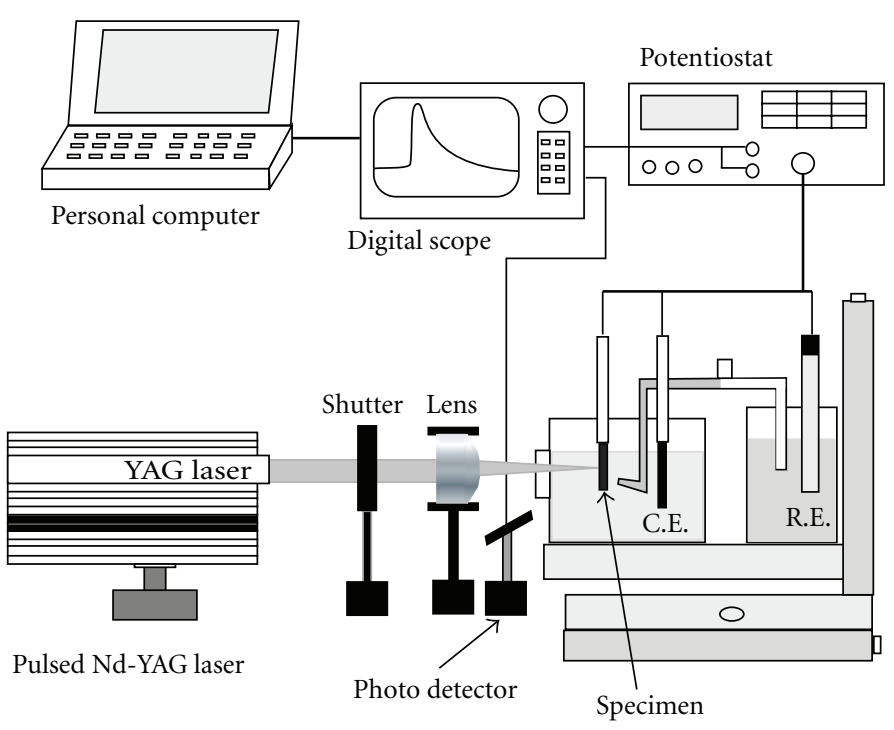

FIGURE 2: Schematic outline of the PRM test equipment.

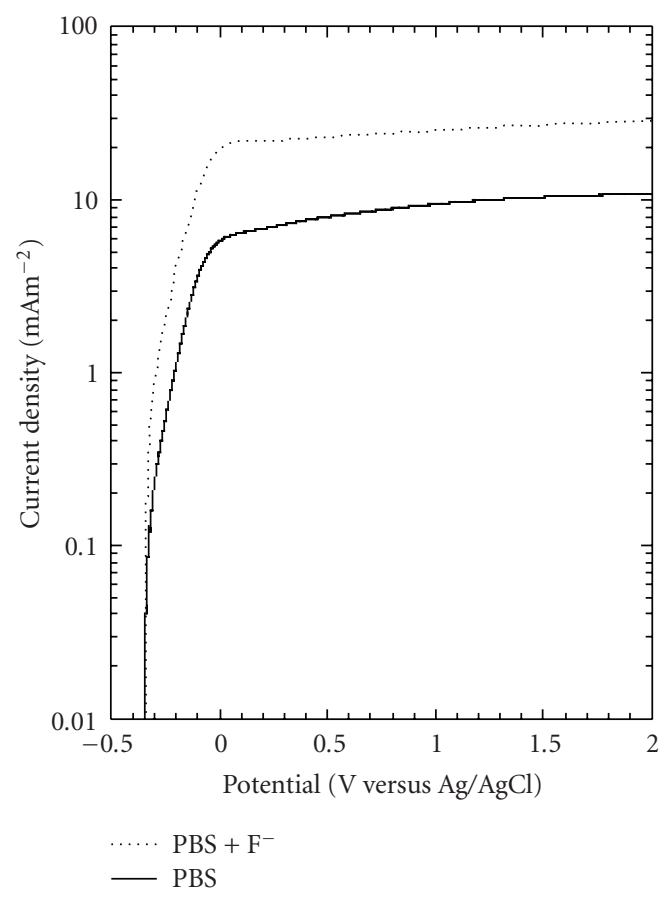

Figure 3: Anodic polarization curves of titanium in PBS and PBS with $\mathrm{NaF}$ at $296 \mathrm{~K}$. Sweep rate: $0.33 \mathrm{mV} \mathrm{s}^{-1}$

Surface observations. The specimen surfaces were examined by a Confocal Scanning Laser Microscope (CSLM, Laser Tech. Co. 1SA-21).

\section{Results and Discussion}

3.1. Polarization Behavior. Figure 3 shows the anodic potentiodynamic polarization curves of electropolished specimens in PBS and PBS with $\mathrm{NaF}$ at $296 \mathrm{~K}$. The rest potential in both solutions are very similar, at $-0.35 \mathrm{~V}$, suggesting

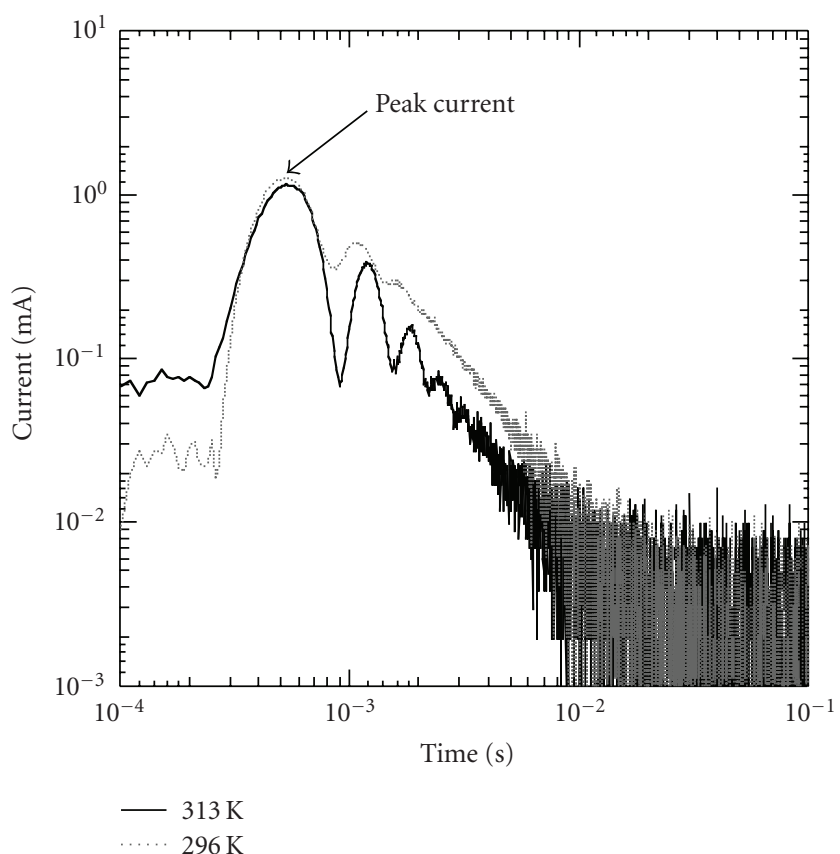

Figure 4: Anodic current transient after laser beam irradiation of titanium in PBS at 313 and $296 \mathrm{~K}$ at $1.5 \mathrm{~V}$.

that the addition of $\mathrm{F}^{-}$ions does not influence the rest potential of the electropolished specimen. With increasing applied potential, the anodic current increases initially and then reaches a steady value in both solutions and the steady current increased with the sweep rate. These results suggest that barrier type anodic oxide film formed on the specimen [27], and further, the constant current increase with the addition of $\mathrm{F}^{-}$ions suggests that $\mathrm{F}^{-}$ions accelerate the dissolution of titanium or formed oxide film. From the polarization curves, the potentials of $-0.2,0,0.5,1.0$, and $1.5 \mathrm{~V}$ were selected for the repassivation experiments. 


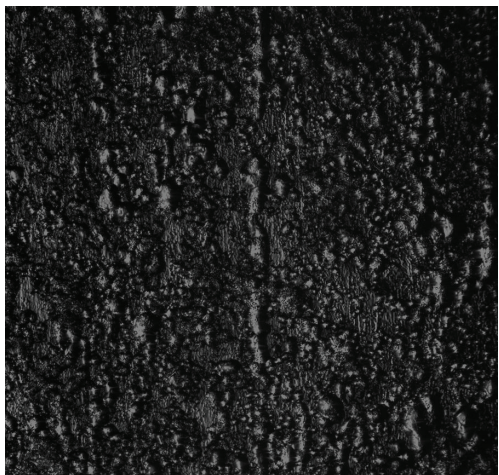

(a)

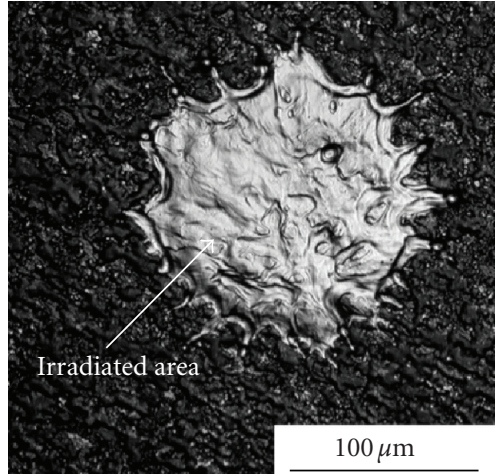

(b)

FIGURE 5: CSLM surface contrast image of titanium specimen (a) before and (b) after laser irradiation in PBS at a constant potential of $1.5 \mathrm{~V}$ at $313 \mathrm{~K}$.

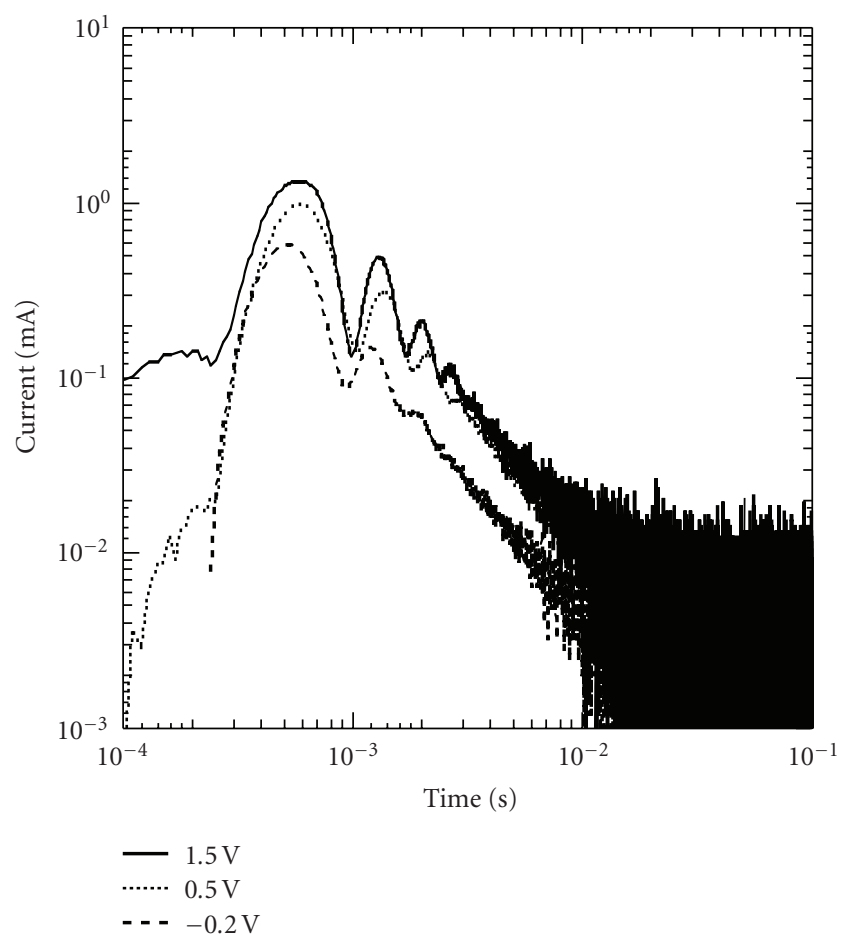

FIGURE 6: Changes in the anodic current after the laser beam was irradiated on titanium in PBS at $0.2 \mathrm{~V}, 0.5 \mathrm{~V}$ and $1.5 \mathrm{~V}$, at $313 \mathrm{~K}$.

3.2. Effect of Temperature and Applied Potential on Repassivation Kinetics. Figure 4 shows the anodic current transient after laser beam irradiation in PBS at 313 and $296 \mathrm{~K}$ at $1.5 \mathrm{~V}$. By the laser beam irradiation, the current increases instantaneously, goes through a maximum, $I_{p}$, at about 0.3 millisecond, then decreases with time to reach a value similar to that before the laser beam irradiation at about 100 milliseconds at both temperatures. The rapid current increase indicates that anodic oxide film was removed by the laser beam irradiation and the decrease in the current means repassivation may have taken place on the irradiated surface. The anodic current is almost the same at both temperatures,

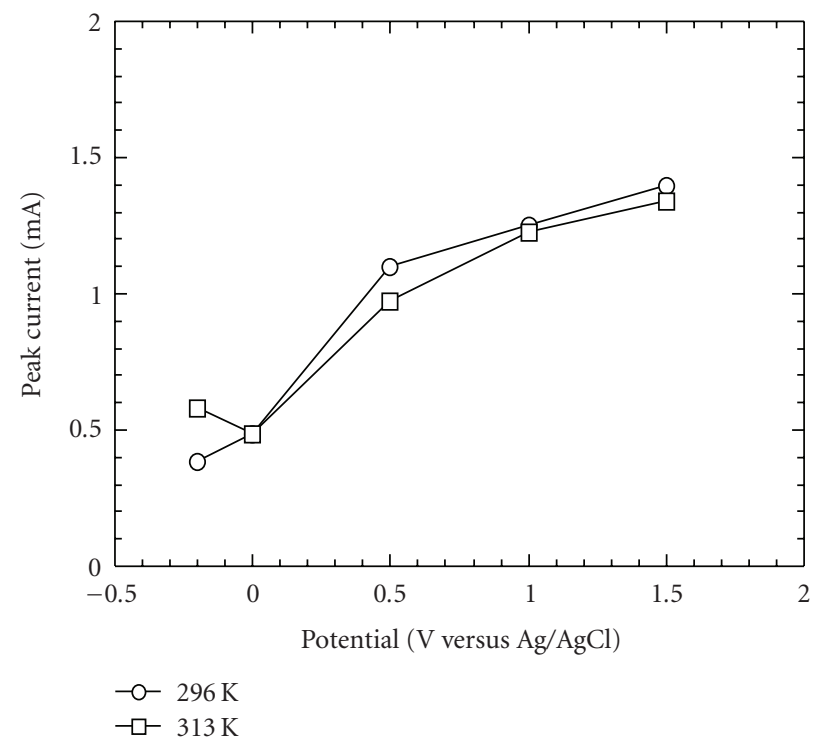

FIGURE 7: $I_{p}$ as a function of applied potential in PBS at 296 and $313 \mathrm{~K}$.

suggesting that the solution temperature does not greatly influence the current transients.

Current fluctuations are observed in the anodic current transients after $I_{p}$ in Figure 4, but the mechanism of the current fluctuations is not fully understood. Assuming that the anodic oxide film removal mechanism is laser ablation, the specimen/solution interface is destroyed and a kind of elastic wave is also generated inside the specimen. Because the average laser beam energy was very low and these experiments were carried out in solutions, the surface temperature of the specimens would be the same as the bulk solution temperature at the time of the current measurements, while at the same time the specimen/solution interface may not be stabilized at the initial stage of the current measurements. Such instabilities at the interface could be causes of the current fluctuations. 


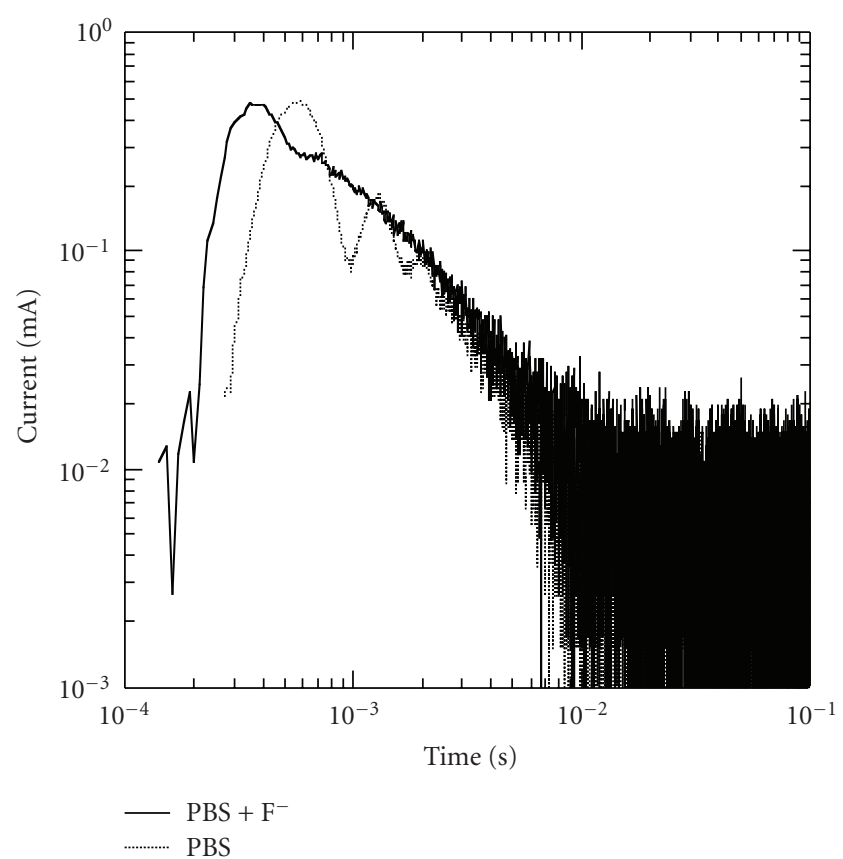

(a)

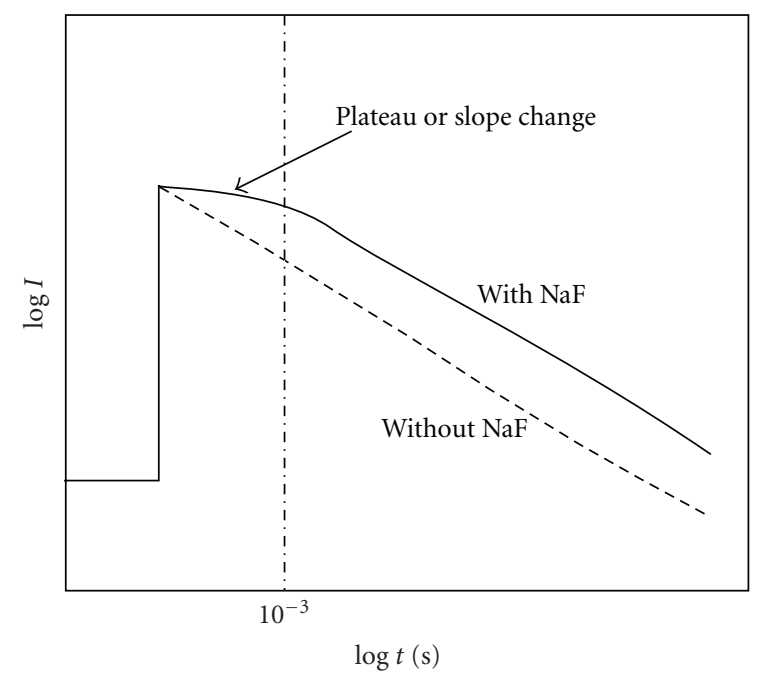

(b)

Figure 8: Anodic current transient after laser irradiation of titanium in PBS and PBS with $\mathrm{F}^{-}$ions at $0 \mathrm{~V}$ at $296 \mathrm{~K}$ and schematic model of slope changes of the current transients by $\mathrm{F}^{-}$ions.

The color of the laser beam irradiated area was the same as the electropolished titanium surface, while the color of other areas was the same as after anodizing. Figure 5 shows CSLM surface contrast images of specimens (a) before and (b) after the laser experiment in PBS at a constant potential of $1.5 \mathrm{~V}$ at $313 \mathrm{~K}$. The anodic film was completely removed at the laser beam irradiated area, the area where the film was removed shows an almost circular outline and the surface appears melted and quickly solidified. The diameter of the irradiated area is about $150 \mu \mathrm{m}$, and this size was almost the same in all the experiments. The current transient in

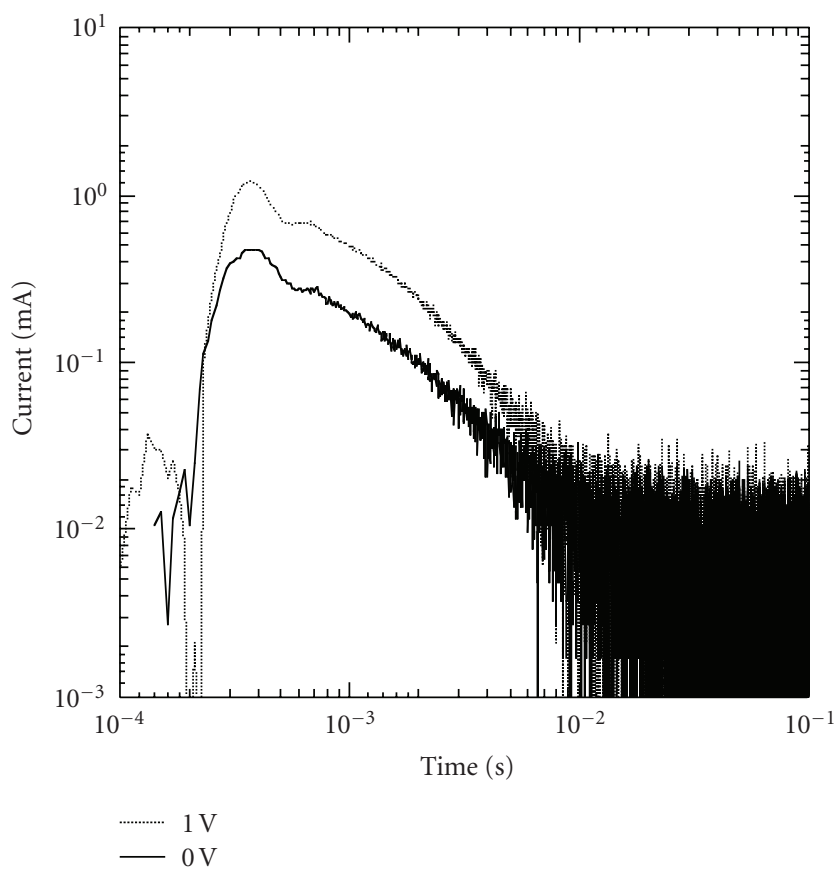

FIGURE 9: Changes in anodic current after laser beam irradiation of titanium at 0 and $1 \mathrm{~V}$ in PBS with $\mathrm{F}^{-}$ions at $296 \mathrm{~K}$.

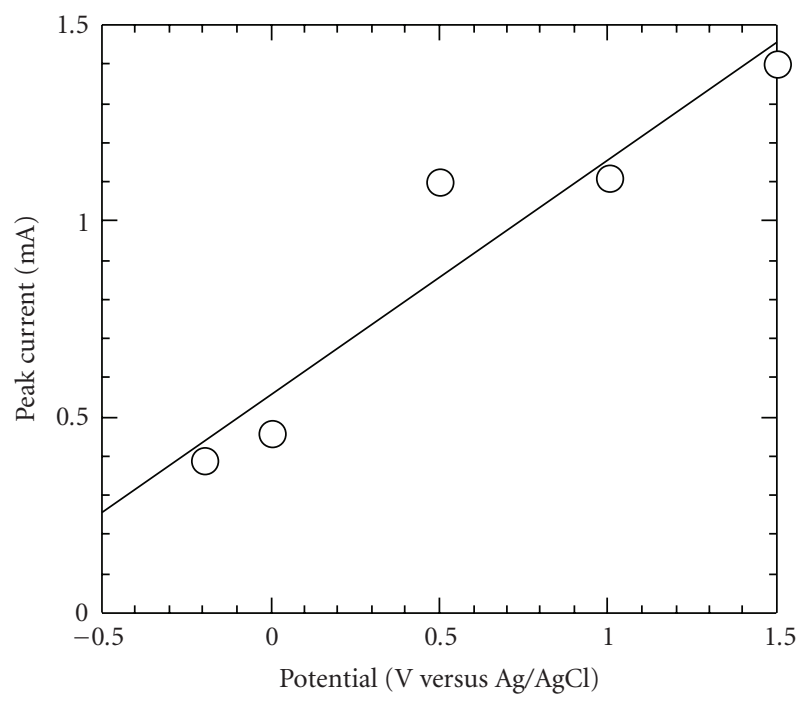

FIGURE 10: $I_{p}$ from Figure 9 as a function of the applied potential.

Figure 4 is related to repassivation of this irradiated area. No corrosion products are observed anywhere on the specimen surface, including not on the laser beam irradiated area. The current transients in Figure 4 and the surface images together suggest that repassivation occurs on the irradiated surface.

In this experiment, the applied potential when measuring the repassivation kinetics by PRM was lower than $2 \mathrm{~V}$, and this means that the oxide film which formed on the irradiated surface is about $10 \mathrm{~nm}$ or thinner [28]. The high electric field oxide film formation theory is generally applied for the oxidation kinetics. In this theory, the electric field inside 


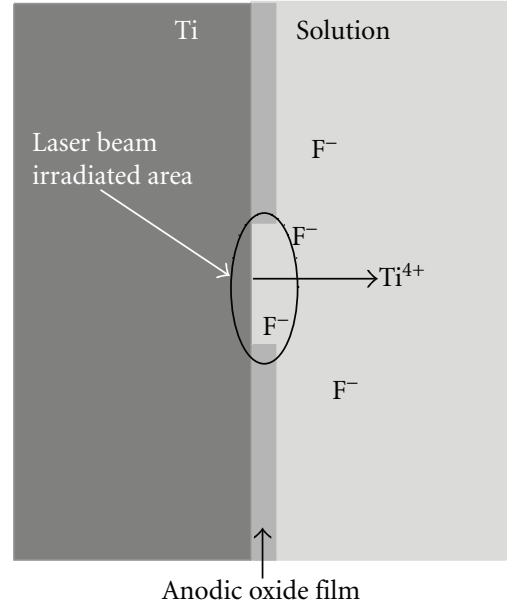

(a) Anodic oxide film removed locally by laser beam irradiation.

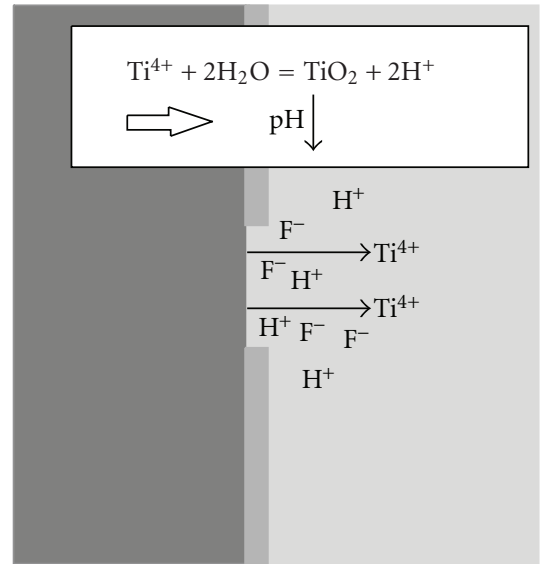

(b) Then $\mathrm{pH}$ changes at the very initial stage after irradiation.

FIGURE 11: Schematic representation of the changes at the titanium/solution interface after laser beam irradiation.

of the thin oxide film is so strong that the velocity of drift of ions is no longer proportional to the electric field, therefore, the rate-determining step of the oxide film growth reaction may be the speed of titanium atom escape from the titanium substrate to the oxide film $[22,29]$. In this situation, the slope of $\log I$ versus $\log t$ curves during oxide film formation must be about -1 , however, the slopes of the $\log I$ versus $\log t$ curves in the experiments are about -1.5 suggesting that the reaction mechanism of repassivation of titanium could be a combination of electrochemical and chemical reactions. During the growth of the oxide film, the strength of the electric field inside the formed oxide film is reduced, because of the constant potential mode of the laser experiments. The electric field changes also produce electrostriction of the anodic oxide film. Hasebe and Alwitt reported electrostrictive behavior of anodic aluminum oxide films $[30,31]$. If the titanium anodic oxide film is brittle, this electrostriction of the anodic film may produce nanoor microcracks inside the film. Then, thorough these cracks, bare titanium surface is exposed to solution and a possible chemical reaction is as follows [32]:

$$
\mathrm{Ti}+4 \mathrm{H}_{2} \mathrm{O} \longrightarrow \mathrm{TiO}_{2}+4 \mathrm{H}^{+} .
$$

This chemical reaction accelerates the oxide film growth kinetics and shows a steep slope in the $\log I$ versus $\log t$ curves. However, details of the chemical reaction and mechanism of oxide film growth are still unclear at present, and further experiments must be done to clarify the phenomena.

Figure 6 shows changes in the anodic current after the laser beam was irradiated in PBS at $-0.2 \mathrm{~V}, 0.5 \mathrm{~V}$, and $1.5 \mathrm{~V}$ at $313 \mathrm{~K}$. The tendency of the current transient is very similar to that in Figure 4 at every applied potential. The current increases with increasing applied potentials suggesting that the main reaction of the repassivation may be the electrochemical reaction. Figure 7 shows $I_{p}$ as a function of the applied potential in PBS at 296 and $313 \mathrm{~K}$. The $\mathrm{I}_{\mathrm{p}}$ increases with increasing applied potential, however, solution temperature has little or no influence on $\mathrm{I}_{\mathrm{p}}$.

3.3. Effect of $F^{-}$ions on Repassivation kinetics. The anodic current transient after laser beam irradiation in PBS and PBS with $\mathrm{F}^{-}$ions at $0 \mathrm{~V}$ at $296 \mathrm{~K}[\mathrm{k}]$ is shown in Figure 8, with a schematic model of slope changes of the current transients by $\mathrm{F}^{-}$ions. The tendency of the current transient is very similar to the previous results (Figures 4 and 6) in both solutions. These results suggest that oxide films are formed on the laser beam irradiated surface also when $\mathrm{F}^{-}$ions are contained in the solution. The $\mathrm{F}^{-}$ions do not greatly influence the total amount of charge, however, the slope of the $\log I$ versus log $t$ plots around 1 millisecond appears to include a plateau like Sakairi et al. [33] has reported suggesting that the slope of the current transient after the laser beam irradiation becomes flatter in corrosive environments. Therefore, the result here suggests that the presence of $\mathrm{F}^{-}$ions accelerate dissolution of titanium or its oxide film at the very initial stage (about 1 millisecond after the laser beam irradiation) of repassivation, and the details of the mechanism of $\mathrm{F}^{-}$ions will be explained in the later part of this section.

Figure 9 shows changes in the anodic current after laser beam irradiation at 0 and $1 \mathrm{~V}$ in PBS with $\mathrm{F}^{-}$ions at $296 \mathrm{~K}$. The changes in the current transients are very similar to the previous figures, however, the slope between 0.3 millisecond and 2 milliseconds is flatter than that after 2 milliseconds. The current increases with increasing applied potential, however, specimens are also repassivated under these experimental conditions. Figure 10 shows the $\mathrm{I}_{\mathrm{p}}$ obtained from Figure 9 as a function of the applied potential, and the $I_{p}$ increases with increasing applied potential.

Figure 11 is a schematic representation of the titanium/solution interface after laser beam irradiation in PBS with $\mathrm{F}^{-}$ions: (a) before the anodic current peak, the anodic oxide film is removed by laser irradiation and titanium dissolution is initiated, (b) next, the $\mathrm{pH}$ changes at the 
laser beam irradiated area at the very initial stage. Overall, after the anodic oxide film removal, titanium is exposed to solution, and titanium starts to dissolve and react with water. This reaction causes the decrease in $\mathrm{pH}$ at the interface and the $\mathrm{pH}$ change and the presence of $\mathrm{F}^{-}$ions at the interface would accelerate the dissolution of titanium or formed titanium oxide film. After several microseconds, the decrease in this local $\mathrm{pH}$ may be compensated to neutral values by the buffering reaction of the PBS. This may be postulated as an explanation why the slope of the initial stage (between 0.3 millisecond and 2 milliseconds in Figures 8 and 9) displays a plateau in $\mathrm{F}^{-}$ion containing solutions.

\section{Conclusions}

The photon rupture method was applied to investigate the effects of the applied potentials, temperature, and $\mathrm{F}^{-}$ions on the repassivation kinetics for commercial pure titanium in PBS, and the following conclusions may be drawn.

(1) All specimens are repassivated after the laser beam irradiation, and the measured slope of the anodic current transient is steeper than what would be expected from high electric field oxide film formation theory.

(2) Current fluctuations are observed at the initial stage of the anodic current transient. These current fluctuations may be caused by instabilities at the specimen/solution interface formed by laser ablation.

(3) The solution temperature does not greatly influence the repassivation kinetics in PBS, while the anodic current peak increases with increasing applied potential and addition of $\mathrm{F}^{-}$ions.

\section{References}

[1] Q. Y. Wang and Y. F. Zheng, "The electrochemical behavior and surface analysis of $\mathrm{Ti}_{50} \mathrm{Ni}_{47.2} \mathrm{Co}_{2.8}$ alloy for orthodontic use," Dental Materials, vol. 24, no. 9, pp. 1207-1211, 2008.

[2] S. Kumar and T. S .N. S. Narayanan, "Corrosion behaviour of Ti-15Mo alloy for dental implant applications," Journal of Dentistry, vol. 36, no. 7, pp. 500-507, 2008.

[3] A. Cremasco, W. R. Osório, C. M. A. Freire, A. Garcia, and R. Caram, "Electrochemical corrosion behavior of a Ti-35Nb alloy for medical prostheses," Electrochimica Acta, vol. 53, no. 14, pp. 4867-4874, 2008.

[4] N. T. C. Oliveira and A. C. Guastaldi, "Electrochemical behavior of Ti-Mo alloys applied as biomaterial," Corrosion Science, vol. 50, no. 4, pp. 938-945, 2008.

[5] D. Q. Martins, W. R. Osório, M. E. P. Souza, R. Caram, and A. Garcia, "Effects of $\mathrm{Zr}$ content on microstructure and corrosion resistance of Ti-30Nb-Zr casting alloys for biomedical applications," Electrochimica Acta, vol. 53, no. 6, pp. 2809-2817, 2008.

[6] M. Karthega, V. Raman, and N. Rajendran, "Influence of potential on the electrochemical behaviour of $\beta$ titanium alloys in Hank's solution," Acta Biomaterialia, vol. 3, no. 6, pp. 1019-1023, 2007.

[7] F. T. Cheng, K. H. Lo, and H. C. Man, "An electrochemical study of the crevice corrosion resistance of NiTi in Hanks' solution," Journal of Alloys and Compounds, vol. 437, no. 1-2, pp. 322-328, 2007.

[8] Y. F. Zheng, B. L. Wang, J. G. Wang, C. Li, and L. C. Zhao, "Corrosion behaviour of Ti-Nb-Sn shape memory alloys in different simulated body solutions," Materials Science and Engineering A, vol. 438-440, pp. 891-895, 2006.

[9] S. L. de Assis, S. Wolynec, and I. Costa, "Corrosion characterization of titanium alloys by electrochemical techniques," Electrochimica Acta, vol. 51, no. 8-9, pp. 1815-1819, 2006.

[10] S. Tamilselvi, V. Raman, and N. Rajendran, "Corrosion behaviour of Ti-6Al-7Nb and Ti-6Al-4V ELI alloys in the simulated body fluid solution by electrochemical impedance spectroscopy," Electrochimica Acta, vol. 52, no. 3, pp. 839-846, 2006.

[11] L. Reclaru and J.-M. Meyer, "Study of corrosion between a titanium implant and dental alloys," Journal of Dentistry, vol. 22, no. 3, pp. 159-168, 1994.

[12] M. A. Khan, R. L. Williams, and D. F. Williams, "In-vitro corrosion and wear of titanium alloys in the biological environment," Biomaterials, vol. 17, no. 22, pp. 2117-2126, 1996.

[13] C. Suba, M. Lakatos-Varsányi, A. Mikó, et al., "Study of the electrochemical behavior of Ti osteosynthesis plates used in maxillofacial surgery," Materials Science and Engineering A, vol. 447, no. 1-2, pp. 347-354, 2007.

[14] P. Handzlik and K. Fitzner, "Electronic properties of anodic oxide films on titanium in phosphate buffered saline solution and artificial saliva determined by EIS method," Archives of Metallurgy and Materials, vol. 52, no. 4, pp. 543-553, 2007.

[15] G. T. Burstein and C. Liu, "Depassivation current transients measured between identical twin microelectrodes in open circuit," Corrosion Science, vol. 50, no. 1, pp. 2-7, 2008.

[16] G. T. Burstein and C. Liu, "Nucleation of corrosion pits in Ringer's solution containing bovine serum," Corrosion Science, vol. 49, no. 11, pp. 4296-4306, 2007.

[17] D. A. Shifler, P. J. Moran, and J. Kruger, "The passivity of iron and carbon steel in anhydrous propylene carbonate solutions," Corrosion Science, vol. 32, no. 5-6, pp. 475-496, 1991.

[18] T. Tsuru and M. Sakairi, "The breakdown and repassivation of passive films on iron whisker and amorphous alloys," Corrosion Science, vol. 31, pp. 361-366, 1990.

[19] R. Oltra, G. M. Indrianjafy, and R. Roberge, "Effect of electrical transient coupling phenomena on the initiation of pits by a pulsed laser," Journal of the Electrochemical Society, vol. 140, no. 2, pp. 343-347, 1993.

[20] M. Itagaki, R. Oltra, B. Vuillemin, M. Keddam, and H. Takenouti, "Quantitative analysis of iron dissolution during repassivation of freshly generated metallic surfaces," Journal of the Electrochemical Society, vol. 144, no. 1, pp. 64-72, 1997.

[21] M. Sakairi, Y. Uchida, and H. Takahashi, "Initial stage of localized corrosion in artificial pits formed with photon rupture on Zn-5 mass\% Al alloy-coated steel," Corrosion Science, vol. 49, no. 5, pp. 2362-2370, 2007.

[22] M. Sakairi, Y. Uchida, and H. Takahashi, "Initial stage of localized corrosion in artificial pits formed with photon rupture on 55mass\%Al-Zn coated steels," ISIJ International, vol. 46, no. 8, pp. 1218-1222, 2006.

[23] M. Sakairi, Y. Uchida, K. Itabashi, and H. Takahashi, "Repassivation and initial stage of localized corrosion of metals by using photon rupture technique and electrochemistry," in Progress in Corrosion Research, E. L. Bettini, Ed., pp. 133-157, Nova Science, New York, NY, USA, 2007.

[24] M. Sakairi, Y. Uchida, and H. Takahashi, "Initial stage of localized corrosion in artificial pit formed on zinc coated 
steels by photon rupture," in Passivation of Metals and Semiconductors, and Properties of Thin Oxide Layers, P. Marcus and V. Maurice, Eds., pp. 561-566, Elsevier, Oxford, UK, 2006.

[25] M. Sakairi, Y. Uchida, K. Itabashi, and H. Takahashi, "Initial stage of pitting corrosion on coated steels investigated by photon rupture in chloride containing solutions," Corrosion Science, vol. 47, no. 10, pp. 2461-2469, 2005.

[26] W. Wilhelmsen and A. P. Grande, "The influence of hydrofluoric acid and fluoride ion on the corrosion and passive behaviour of titanium," Electrochimica Acta, vol. 32, no. 10, pp. 1469-1474, 1987.

[27] H. Habazaki and K. Shimizu, "Crystallization of anodic oxides on valve metals," Journal of the Surface Finishing Society of Japan, vol. 57, no. 1, pp. 51-57, 2006.

[28] T. Ohtsuka, M. Masuda, and N. Sato, "Ellipsometric study of anodic oxide films on titanium in hydrochloric acid, sulfuric acid and phosphate solution," Journal of the Electrochemical Society, vol. 132, no. 4, pp. 787-792, 1985.

[29] U. R. Evans, The Corrosion and Oxidation of Metals, Arnold, London, UK, 1996.

[30] T. Hasebe and R. S. Alwitt, "Nonlinear dielectric properties of anodic aluminum oxide films," Journal of The Electrochemical Society, vol. 154, no. 11, pp. C626-C630, 2007.

[31] T. Hasebe, Study on dielectric and electrostrictive properties of aluminum anodic oxide films-origin of heat generation in aluminum electrolytic capacitors, Ph.D. thesis, Hokkaido University, Sapporo, Japan, March 2009.

[32] M. Pourbaix, Atlas of Electrochemical Equilibria in Aqueous Solutions, NACE International Cebelcor, Houston, Tex, USA, 1974.

[33] M. Sakairi, K. Itabashi, and H. Takahashi, "Initial stage of localized corrosion of Al-9 mass\% Si coated steels after removal with a photon rupture method in solutions," Zairyo to Kankyo, vol. 52, no. 10, pp. 534-538, 2003. 